\title{
Efforts for early detection of child abuse - Actual condition survey of infant dental checkups at health centers
}

\author{
Shigeru Watanabe*, Hiromi Ohthuka, Aiko Hoshiai, Yukiko Yamamura, Eri Sambuichi, Yayoi Kanehisa and Iwai Tohnai \\ Meikai University School of Health Sciences, Department of Oral Health Sciences, Akemi 1, Urayasu, Chiba 279-8550, Japan
}

\begin{abstract}
A questionnaire was conducted at health centers that provide dental checkups for infants in order to make use of infant dental checkups for early detection of neglected children. The questionnaire was collected from 49 health centers in Saitama Prefecture, and the aggregation of the collected data shows that there were differences between the areas in the number of dental checkups in one year, the rate of dental checkups, handling of people who have not received dental checkups, and the way in which dentists in charge of dental checkups are selected. In addition, differences were found in the content of checkups and the length of checkups, depending on the dentist, and there were many opinions that these should be unified. There are 24 areas that do not have a follow-up system for families after dental checkups, but none of the areas has a dental network.
\end{abstract}

The survey shows that there are differences between the areas in infant dental checkups at health centers established in cities, towns, and villages. In the future, we intend to equalize the content of dental checkups across all the areas and change the system to make not only dental checkups but also family checkups possible at the same time, so that we can support families who have neglected their children.

\section{Introduction}

The United Nations General Assembly adopted the Convention on the Rights of the Child in 1989, and Article 19 of the Convention included provisions for protecting children from abuse and neglect for the first time. Against this background, the number of child abuse cases (number of cases handled) has come to be reported from child consultation centers all over Japan since 1990. In 2000, the Child Abuse Prevention Act was enacted to strengthen cooperation among institutions involved in child abuse prevention. The number of cases handled has never dropped from 1101 of FY 1990, and it exceeded 150,000 in FY 2018, with psychological abuse at 55\% and neglect at $30 \%$ [1], suggesting that child abuse that cannot be seen is spreading deeply in families. During the 11 years from 2003 to 2014, the cumulative number of deaths due to abuse reached 1000 . According to the statistics for FY 2018, the number of deaths due to abuse was 65, or 1.2 per week. Child abuse is now a serious social problem in Japan that cannot wait any longer to be addressed [2].

Caries and periodontal disease are typical lifestyle-related diseases, and conditions in the oral cavity are strongly influenced by the living environment. It has been reported that caries spreads in the oral cavity of children who are forced to lead improper lives due to poverty caused by their parents' divorce or illness of their parents [3].

In Japan, it is legally obligatory for children aged 1.6 years old and three years old to have a dental checkup, and more than $90 \%$ of children in Japan have a dental checkup every year. This checkup is conducted at health centers located in cities, towns and villages throughout Japan, and dentists in private practice in those areas are in charge of the checkups. If it is possible to conduct a survey on the living environment of children at home in addition to checking for their caries, it is possible to grasp the children's condition at home. However, it is not clear how dental checkups are conducted at health centers, so a questionnaire was conducted at this time to investigate the actual situation.

\section{Method}

In order to grasp the current situation of dental checkups for 1.6-year-olds and 3-year-olds, we conducted a questionnaire survey of 77 cities, towns, and villages in Saitama Prefecture, which is adjacent to Tokyo, and received responses from the health centers of 49 cities, towns, and villages (64\% response rate). The respondents in 43 areas were public health nurses, and the respondents in six areas were hygienists.

The questionnaire included (1) the number of dental checkups for the past one year, (2) the dental checkup rate for the past one year, (3) handling of those who had not had dental checkups yet, (4) how to decide which dentist is to be in charge of dental checkups, (5) differences among the dentists, (6) follow-up system for children with problems after a dental checkup, and (7) whether or not the dentist in charge of dental checkups attended a training session for dental checkups.

This study was conducted in accordance with the regulations issued by the Meikai University Ethics Committee.

\section{Results}

(1) Dental checkups were conducted three to six times a year in 34 areas, which outnumber all the others. They were conducted only once a year in nine areas, and once a month in five areas.

(2) In fiscal year 2018, the checkup rate was in the range of 90 to $95 \%$ in 20 areas for 1.6-year-old checkups and in 29 areas for 3-year-old

${ }^{\star}$ Correspondence to: Shigeru Watanabe, Meikai University School of Health Sciences, Department of Oral Health Sciences, Akemi 1, Urayasu, Chiba 2798550, Japan, E-mail: ibishigeru@yahoo.co.jp

Received: February 01, 2020; Accepted: February 19, 2020; Published: February 21,2020 
checkups. Similarly, the checkup rate in the range of 95.1 to $100 \%$ was found in 29 areas for 1.6-year-old checkups, and the checkup rate of the same range was found in 20 areas for 3-year-old checkups (Of these, the checkup rate of $100 \%$ was found in three areas.).

(3) For those who had not had a dental checkup, ways to handle the situation were to send a postcard ( 21 areas), to make a phone call (14 areas), to do nothing (seven areas), to make a home visit (six areas), and no response (one area) in the order of commonality.

(4) The areas where they requested the local dental association to select dentists for dental checkups numbered 45, outnumbering other cases, while the areas where the health center independently selected local dentists numbered four.

(5) There were 28 areas where the content of the dental checkup (multiple answers allowed) varied from one dentist to another. There were 21 areas where the present situation posed no problem while there were eight areas where they thought that the methods should be unified. In two areas, they thought the purpose of the dental checkups should be clarified, and in one area, they thought that a qualification system should be adopted for dental checkups.

(6) Follow-up systems after health checkups have been established with multiple professions, mainly public health nurses, in 25 areas. Twenty-four areas do not have any follow-up systems. No area has a dental network.

(7) 28 areas were willing to attend training sessions on dental checkup methods if such training sessions were held. 21 areas thought that there was no need for them.

\section{Discussion}

According to the 2013 Unicef Innocenti Report Card 11: Child Well-being in Rich Countries [4], the Japanese children's world is no longer in a good environment. That is to say, in comparison with 31 countries, Japan was ranked first in both "education" and "risk in daily life," maintaining its reputation as a developed country, while ranked 16th in "health and safety" and 21st in "material wealth (poverty)".

In Japan, the improvement of living standards and the spread of interest in oral health have helped to ensure a caries-free world for children (the average number of caries per child aged twelve years old is 1.1 teeth; the percentage of patients with caries at the age of five is $42.8 \%$ [5]). However, children's oral diseases, caused by poverty, neglect, etc. due to their parents' divorce, have become a problem, and there are growing expectations that an SOS from the oral cavity of children can be used for early detection of child abuse.

Therefore, in order to apply the dental checkups for children aged 1.6 years old and three years old, which are required by law, to the survey of the children's families, we investigated the actual conditions of the dental checkups currently being conducted.

In Japan, health centers established in each local government, city, town, and village play a central role in providing services related to people's health. Therefore, it can be imagined that the activities of health centers vary like the population and policies vary from one municipality to another.

The number of checkups is only once a year in nine areas, but the checkup rate in such areas tends to be low. In addition, it is considered that there is a high tendency of neglect among households that did not come to dental checkups, but in seven areas, no measures were taken for households that did not come to dental checkups. It is considered necessary to set as many opportunities as possible for dental checkups and to make a home visit to investigate families that have not come for dental checkups. However, home visits were conducted in only six areas.

Most of the dentists in charge of dental checkups were dispatched from local dental associations. There were many differences among dentists in the content of checkups and the length of checkups ( 28 areas), and there were many opinions that these should be unified. 24 areas have not established a follow-up system for families after dental checkups. No area has a network for dental treatment.

Based on the results of the questionnaire conducted at the health centers, the following are considered to be issues to be promoted in the future.

1. Establish a system that makes it possible for health centers in the prefecture to engage in activities on the same level by cooperating and sharing information with each other.

2. Make a home visit for those who have not had a dental checkup with the aim of achieving the dental checkup rate of $100 \%$.

3. Establish a follow-up system after dental checkups at each facility. Establish a dental network.

4. Select dentists for dental checkups from among those who are enthusiastic about pediatric dentistry or abuse prevention activities.

5. Hold training sessions for those engaged in dental checkup services.

In the future, we intend to reflect this information in the local community and establish a system for supporting families who neglect their children by not only checking children's teeth but also conducting family surveys at the same time as infant dental checkups.

\section{Acknowledgments}

The authors thank the staff of each health center in Saitama for cooperating with the questionnaire in this study. This research was supported by the 2019 Meikai University Miyata Research Grant.

\section{References}

1. https://www.mhlw.go.jp/stf/houdou/0000190801_00001.html.

2. Watanabe S, Sato T, Kawasaki H (2014) Oral environment reflects life-Action from dentistry for the Child neglect-. XXth International Congress on Child Abuse and Neglect. Nagoya, Japan.

3. Schwartz S (1977) Oral manifestations and legal aspects. JADA 95: 586-91.

4. Abe S, Takezawa J (2013) Unicef Innocenti Report Card II. Child well-being in rich countries. Comparing Japan. The Japan Committee for UNICEF, Tokyo, Japan.

5. https://www.mext.go.jp/component/b_menu/other/__icsFiles/ afieldfile/2019/03/25/1411703_03.

Copyright: (C2020 Watanabe S. This is an open-access article distributed under the terms of the Creative Commons Attribution License, which permits unrestricted use, distribution, and reproduction in any medium, provided the original author and source are credited. 